\section{Pedro Chequer}

Joint United Nations Programme on HIV/AIDS - Brazil. Brasília, DF, Brasil

\footnotetext{
Correspondence:

Pedro Chequer

UNAIDS-Brazil

EQSW 103/104-Lote 1 - Bloco C

2o. andar - Setor Sudoeste

70670-350 Brasília, DF, Brasil

E-mail: chequerp@unaids.org
}

\section{Foreword}

Within the field of public health, the HIV epidemic has brought out some practices and approaches that need to form part of the list of essential activities with a view to formulating public policies. There is no doubt that systematically investigating the characteristics of the population's knowledge, perceptions, behavior and practices is within this scope, as an essential source of feedback for public policies that have been implemented and guidance regarding their revision, reformulation or even comprehensive change in strategic focus. Along these lines, the National STD/AIDS Program has sought to systematically investigate the characteristics of the sexual behavior of the Brazilian population and other psychosocial and cultural characteristics, involving their knowledge, perceptions and attitudes, with the aim of establishing baseline and trendmonitoring parameters, thus creating a critical mass of information for monitoring and assessing public policies that have been implemented.

Certain reference parameters have been established within the field of HIV infection, and these make it possible to estimate the magnitude of the epidemic and, particularly, to evaluate its trends and developments in different segments of the population. Along traditional public health lines, it is sought to base decision-making on case incidence studies, analysis of mortality profiles, special studies on infection prevalence and, very rarely, the costs involved and the operational difficulties.

Monitoring of infection rates includes establishing prospective cohorts or using recently proposed laboratory techniques for estimating incidences. Unfortunately, the latter have not yet been refined sufficiently for them to provide an acceptable degree of reliability.

Despite the importance of these strategies together and each one in particular, considering that they are directed towards well-defined objectives, none of them surpasses behavioral studies as an essential and indispensable input for formulating policies aimed at health promotion and primary prevention. Such studies make it possible to draw up scenarios and better delineation of trends, provided that they are repeated systematically and periodically. Within this focus, the second survey evaluating "Sexual Behavior of the Brazilian Population and Perceptions of HIV/AIDS" was undertaken in 2005. This followed the same lines as in the survey conducted in 1998, in order to implement similar and comparable investigations that, when added to other studies carried out previously, would enable comparative analysis and trend evaluation.

Investigations of this nature are also useful for enabling international comparisons between indices and for promoting the establishment of horizontal cooperation between institutions and between countries. In this respect, the Brazilian investigation and research response also sets an example.

In Brazil, the practice within the National STD/AIDS Program has been to use the results from investigations and research starting from ethics parameters and respect for citizens' rights. Investigations aimed at measuring behavioral characteristics have been used as a reference point for formulating public policies within the fields of information dissemination, health promotion and prevention. In reality, despite the emphasis and recognition of the Brazilian response within the field of care and attention, and the country's prominence in the fields of communication, dissemination of information and prevention strategies, there is certainly still much to be done. 
In drawing up proposals for this field, it has been fundamentally important to harmonize the proposals and actions between government and society, in a process that has often been conflictive but always in touch with the ultimate, more comprehensive objectives. This dialogue between government and society encourages practices in which the exercising of citizens' rights and the commitments of the State converge, to their common advantage. This process is in consonance with the principles established in the Brazilian constitution and it reflects the norms and principles of the Sistema Único de Saúde SUS - Brazilian National Health System), in which social control and participation are indispensable and inalienable aspects of the modus operandi of the public system.

With regard to the constitutional principle of health as each citizen's right and the State's duty, the field of AIDS has been the most concrete example of the implementation of constitutional norms within the field of healthcare. On the other hand, this process has taken place without losing sight of scientific principles in formulating program norms and implementing evidencebased practices: popular participation, social control and healthcare practices with scientific backing.

Differently from what may be observed in some parts of the world, social participation occurs not only in carrying out activities and implementing specific actions, but also within the process of formulating public policies. Society is a privileged player at the various levels and forums for decision-making, formulating guidelines, establishing priorities and defining technical standards. This common and concerted effort involving different levels and spheres of government has been decisive in achieving the observed changes, through strengthening and expanding practices in which prevention of HIV infection and other sexually transmitted infections is seen to be increasingly incorporated into daily life, particularly among the younger segments of the population.

Mass communication has, since the outset, been one of the supports for disseminating information and generating a debate on this issue. In this regard, the important role played by the media must be emphasized. This role continues today, as an important aspect of the process of continuing education, an ever-present source for generating debate and a privileged space for critical analysis of actions that have been developed.

The objectivity of government messages and their emphasis on questions that were considered polemical or even taboo in most other countries - such as sexuality, sexual practices and condom use - has been one of the marked characteristics of the Brazilian response, notwithstanding the initial difficulties caused by pressure from conservative religious sectors. In this case too, the scientific evidence and the need for immediate action prevailed, and the fruits from this focus are abundantly recognized. Brazil did not wait for significant conservative social segments to become convinced of the importance of this direct and clear focus, but made the State policy an instrument in this change.

Having made these points, it is with satisfaction that I now see the first published results from the 2005 survey "Sexual Behavior of the Brazilian Population and Perceptions of HIV/AIDS”, compared and contrasted with the results from the previous version of this survey (de 1998), thus renewing and expanding the fruitful partnership between the Centro Brasileiro de Análise e Planejamento (CEBRAP - Brazilian Center for Analysis and Planning) and the Ministry of Health. 